
the investigation and prosecution of cases involving

Kelly L. A research review on the reporting, investigation and prosecution of rape cases. London, Her Majesty's Crown Prosecution Service Inspectorate, 2002.

Temkin J. Reporting rape in London: a qualitative study. Howard J Crim Justice 1999; 38:

\title{
One in four: Providing emotional support to female victims of domestic violence
}

It is estimated that one woman in four suffers domestic violence at some time in her life and that domestic violence accounts for one-quarter of all violent crime. According to the 2001 British Crime Survey, there were 499000 cases of domestic violence in England and Wales. ${ }^{1}$ Two women are killed every week by an abusive partner. ${ }^{2}$

Domestic violence can include verbal abuse, restrictions on contact with family members or friends, threats, physical assaults, rape and, ultimately, murder. Increasingly, men who have suffered domestic violence are coming forward to report abuse at their hands of their partners, both male and female. It should be noted here that Victim Support fully recognises that domestic violence does not only impact on women, and that its services are available equally to male and female victims and those in same-sex relationships. It is generally recognised by professionals in the social care sector that domestic violence is rarely a one-off event and can become increasingly serious and more frequent over time.

Victim Support is the national charity that helps people cope with crime. The organisation's community-based local groups, the Witness Services (based in the criminal courts) and the Victim Supportline, all have regular contact with female victims of domestic violence. Trained staff and volunteers offer emotional support, practical help and information - on a free and confidential basis - to more than one million victims of crime (including victims of domestic violence) every year.

As well as providing services to victims and witnesses, the organisation campaigns regularly for the introduction of criminal justice and social policies that take into account the needs and interests of victims of crime and witnesses. In February 2002, Victim Support's major campaign, Criminal Neglect ${ }^{3}$ called for a collaborative response from agencies and organisations outside the criminal justice system to address victims' and witnesses' needs.

The Criminal Neglect report insists, and demonstrates, that many victims of crime are effectively re-victimised by insensitive and inappropriate treatment by agencies and organisations, including housing providers, insurance companies and health care professionals. For example, the campaign urged health care professionals, particularly in accident and emergency departments, to be more aware of the effects of crime on patients and to offer them information about other agencies. Victim Support is aware that many victims of domestic violence will not go to the police as their first port of call, and could subsequently be faced with a lack of information and understanding in hospitals when they present their injuries to staff.

Key to Victim Support's success in helping victims of domestic violence is the organisation's multi-agency approach. The charity's Code of Practice states that 'Victim Support has a role in developing effective service provision for victims of domestic violence, working in partnership with other local agencies, to ensure the best use of resources'. 4

The STAR Project (Survival Through Abusive Relationships) is an example of how Victim Support uses this approach to help address the needs of women who are affected by domestic violence. It was set up as a result of a partnership between the Women's Project (which carried out the research that identified the need for the project) and Victim Support Avonvale's North Somerset Schemes. NSDAF (North Somerset Domestic Abuse Forum), North Somerset District Police, the North Somerset Community Legal Services Partnership and the Soroptimists have all lent their support to the initiative. Victim Support Avonvale describes the aim of the STAR Project as 'providing positive advice as to a person's choices together with appropriate practical support'. 5 In 2000, the Project received 30 domestic violence referrals; in 2001, that number had risen sharply to 117 referrals. ${ }^{5}$

One of the Project's volunteers describes her 2 years' work as rewarding because, she says, it enables women to make decisions for themselves. 'They can plan in advance what they are going to do if they decide to leave, rather than suddenly find themselves in a situation of having to sort things out at a difficult and inconvenient time. Some women do not want to leave but by knowing the choices that are available to them, they are more able to live with the situation. 5

Listening to abused women is important work for staff and volunteers at the Victim Supportline. Currently, the Supportline receives around 1650 calls a month (G Gridley, personal communication) from victims of a wide variety of crimes, and for some people it is their first point of contact after a crime. Between 2000 and 2001, the Victim Supportline took 17922 calls, 1369 of which were from victims of domestic violence. ${ }^{6}$

It is clear that, soon after an incident, many people want to talk to somebody. They need to make sense of the crime and want to know why they have, apparently, been singled out. When the phone rings in the Supportline office, the crime could range from a mobile phone theft or a burglary, to an abusive relationship, a rape or the murder of a relative. 
One of the Supportline co-ordinators, Gill Gridley, points out that there is "no such thing as a typical call about domestic violence'. She describes the nature of the calls as varied as it depends on the stage at which the woman is at in the relationship. Many women could be said to be 'in denial' about the experience of being a victim and take a long time to admit to themselves, and to others, that they have been abused or assaulted and that their partner or husband is responsible. This can be for a number of reasons; for example, the woman can feel very committed to the relationship and is trying hard to make it work, regardless of the emotional, mental and physical toll that it is taking on her and those around her. The abuse can also become a family secret, so the woman ends up blaming herself.

Excuses for the abusive behaviour are also common; for example, taking the blame for the breakdown of the relationship and the subsequent abuse, and defending the partner's role as a loving parent. However, there is clearly an issue here about the psychological damage suffered by children who are caught up in abusive relationships.

The trained staff and volunteers on the Victim Supportline do not give advice, but they can offer 'emotional support' - a listening ear - and will refer women to other specialist agencies, including Refuge and Women's Aid, if necessary. Gridley says it is essential that victims of domestic violence talk to somebody about their experiences. She stresses that the Supportline does not give advice, such as urging women to leave the relationship. Instead, various options can be suggested and discussed with the caller.

Staff and volunteers in around 300 community-based groups in England, Wales and Northern Ireland (Victim Support Scotland is an autonomous organisation under the Victim Support umbrella) provide emotional support and practical help to victims of crime, witnesses, their families and friends. The service is free and confidential, and the help is provided whether or not the crime has been reported to the police or when it happened.

As Victim Support provides an outreach service, all of the staff and volunteers in the local groups, the criminal courtbased Witness Services and the Victim Supportline receive basic awareness training on the impact of domestic violence. Staff and volunteers who opt to work specifically with victims of domestic violence undergo intensive training.

A number of Victim Support's local groups have gone a step further, as we have seen with the STAR Project, and have set up dedicated services for victims of domestic violence. Trained staff and volunteers will give the woman time to talk about her experiences and feelings and provide information about the options available to her. They can also help with practical issues or liaise with other organisations, including housing authorities.

If the woman decides to report the crime to the police, the local Victim Support group will provide information about the criminal justice system and police procedures. If the case goes to court, the Victim Support-operated Witness Service (based in every criminal court in England and Wales) can provide her with emotional support and information. Witnesses and victims of crime who use the Service can get information about court procedures, pretrial visits and help with filling in forms. Importantly, many also provide separate waiting areas where the woman can sit at a comfortable distance from the perpetrator's family or friends.

Witnesses are supported before, during and after the trial, although for legal reasons the staff and volunteers do not discuss the evidence. However, that does not prevent them from playing a significant part in helping witnesses, victims of crime, their families and friends with coping with the stress of appearing in court. A recent Home Office survey on the Witness Service found that $97 \%$ of those questioned were either 'very satisfied' or 'fairly satisfied' with their experience of the Witness Service. ${ }^{7}$ This positive feedback is very encouraging and clearly shows that the Service's work is effective and widely appreciated. Our staff and volunteers will continue their hard work in the local groups, the Witness Service and on the Victim Supportline to provide a comprehensive service to women who have suffered domestic violence.

Statements on funding and competing interests

Funding. None declared.

Competing interests. The author is Media and PR Officer for Victim Support.

Andrew Buckingham, BA (Hons), PG Dip

Media and PR Officer, Victim Support, Communications Department, Victim Support National Office, Cranmer House, 39 Brixton Road, London SW9 6DZ, UK. Tel: +44 (0) 207896 3750. E-mail: andrew.Buckingham@ victimsupport.org.uk

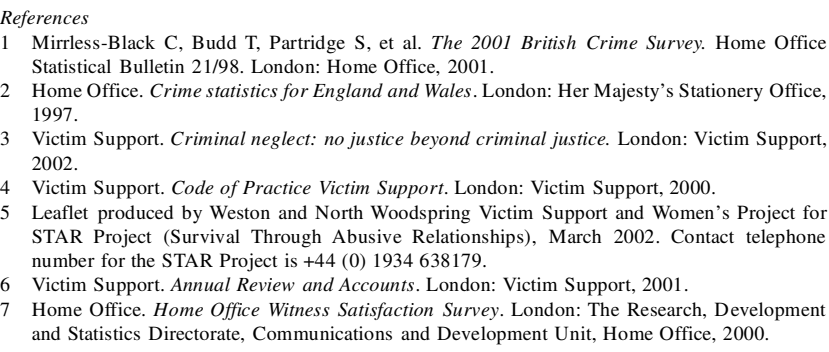

Contact Information. The Supportline can be contacted by callers requiring emotional support on 08453030900 (telephone number for UK callers only). Calls are charged at the local rate, and the line is open on weekdays between 9am and $9 \mathrm{pm}$, weekends from $9 \mathrm{am}$ to $7 \mathrm{pm}$ and bank holidays between $9 \mathrm{am}$ and $5 \mathrm{pm}$. For general information about the Victim Supportline or to volunteer call +44 (0) 20 7896 3923. Website: www.victimsupport.org

\section{Sexual abuse and learning disability}

Sexual abuse of any person is abhorrent whether they are disabled or non-disabled. The emotional and physical repercussions are many for the abused person. Sexual abuse of people with learning disability has been described as 'thinking the unthinkable'. The incidence of reported sexual abuse is high. ${ }^{1}$ This applies only to the known cases: how many other cases remain undetected?
Although the focus is often placed on sexual intercourse (vaginal or anal) there are other aspects of sexual abuse, which has been defined as follows:

- Where sexual acts are performed on or with someone who is unwilling or unable to consent to those acts. ${ }^{2}$

- Any sexual contact which is unwanted and/or unenjoyed by one partner and is for the sexual gratification 